\title{
Preliminary Morphometric Study on Gill Development in Black Sea Bream (Acanthopagrus schlegeli)
}

\author{
Tamotsu IwAI ${ }^{* 1}$ and G. M. Hughes ${ }^{* 2}$
}

(Received March 12, 1977)

\begin{abstract}
The surface to volume ratio for the gill system was examined in larvae of the black sea bream by using positive transparencies of serial sections projected on a rectilinear grid. Morphometric data showed that the ratio for gill filaments decreases markedly at the transitional stage from yolk sac to exogenous food source. Larvae at the end of the yolk sac stage probably have considerable difficulties with gill respiration, as well as food searching.
\end{abstract}

The development of the gills has been investigated for relatively few species of fish and a complete range of morphometric data is only available for small-mouthed black bass $^{11}$, rainbow trout ${ }^{21}$, herring and plaice ${ }^{3)}$. In addition some measurements have been made for later stages of development of a number of Indian air breathing fish ${ }^{4,5)}$. During development there are changes in the site of gas exchange which are related both to the relatively higher metabolic rate of these stages and the greater values for the ratio between surface and volume of the whole organism. It seems certain that cutaneous respiration plays an important role during the earlier stages but the gas exchange function is taken over by the gills as they develop. During development there are also changes in the type of metabolic substrate which might be correlated with the changing size of the yolk sac and consequent changes in respiratory quotient.

The relationships between these different aspects of respiratory function in the early stages of fish are clearly of great importance and any misadjustment could lead to increased mortality during development. Knowledge of the relationships would certainly be of value in the design of the most ideal conditions for the culture of important food fish such as the black sea bream.

\section{Materials and Methods}

The developmental stages used in this study were made available from artificially fertilised eggs in the laboratory of Kyoto University at Maizuru. Hatched larvae were reared in containers at water temperatures of 17.8 to $21.1^{\circ} \mathrm{C}$. Various organisms ranging from wild plankton collected from coastal waters to laboratory-cultured rotifer, Brachionus,

*1 Department of Fisheries, Kyoto University, Kyoto, 606 Japan (岩井 保：京都大学震学部水産 学教室).

*2 Research Unit for Comparative Animal Respiration, University of Bristol, Bristol BS8 1UG, England (G. M. HUGHes: プリストル大学). 
and Artemia nauplii were used as a food source. Larvae were fixed at varying stages from 0 to 25 days after hatching using $10 \%$ formalin.

The material was embedded in paraffin wax and serially sectioned approximately transverse to the main body axis at $7 \mu \mathrm{m}$ thick. The slides were stained in haematoxylin and eosin, and inspected under the light microscope. Photomicrographs were taken of all the sections of specimens in the 5, 8, 12, 20 and 25-day material. Positive transparencies from these films were projected on to a rectilinear grid. Counts were made of the points and intersections of this grid with parts of the developing gill system as indicated in Fig. 1. A distinction was made between points and intersections with the gill arches themselves ( $P_{a}$ and $\left.I_{a}\right)$ and of the gill filaments $\left(P_{f}\right.$ and $\left.I_{f}\right)$ which later increased in surface because of the developing secondary lamellae. Although counts were made for all sections, it was

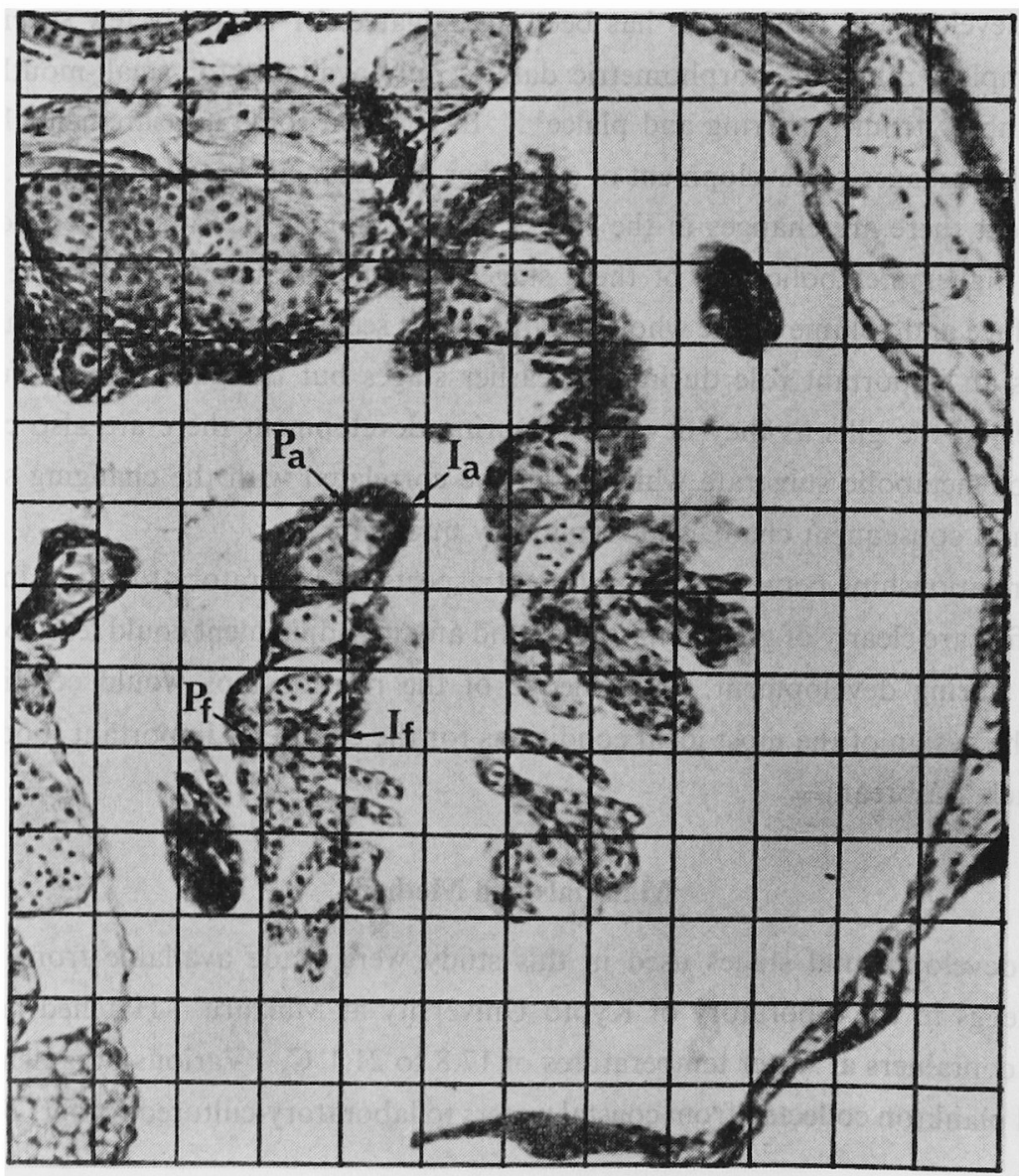

Fig. 1. Photomicrograph of section through the gill arches on one side of a 25-day larva and superimposed rectilinear grid. Intersections of this grid with the arch itself $\left(I_{a}\right)$ and gill filaments $\left(I_{f}\right)$ are shown. Points counted for the arch $\left(P_{a}\right)$ and filaments $\left(P_{f}\right)$ are also indicated. 
found that no statistical difference would have occurred if only every third section of the 25-day material had been used. Morphometric methods were similar to those suggested by HuGHEs ${ }^{6}$.

\section{Results}

Description of early larval stages The newly hatched larvae were about $2.2 \mathrm{~mm}$ long. The large ovoid yolk sac with the posteriorly placed oil globule was one of the outstanding characteristics of these larvae at the floating stage. There was no indication of jaws. The anterior half of the gut was in the course of formation, though the posterior half was observed as a canal. The eye and ear capsules were proimnent but the retina was nearly colourless. The larvae were rather inactive, and floated with the yolk sac uppermost and head directed slightly downwards.

By the 3rd day after hatching the tail region of the larvae had extended, and their total length was about $2.8 \mathrm{~mm}$. The yolk sac was reduced and had become less deep. The mouth and operculum were open and the anus and ureter were prominent. The larvae floated with the yolk sac uppermost, but they often sank head first and slowly swam upright. When they rested the yolk sac once more became uppermost.

In 4-day larvae, about $3 \mathrm{~mm}$ in total length, the yolk sac was very small. The entire gut was complete, and peristaltic movements were occasionally observed. The eyes became pigmented by melanophores. Naked neuromasts were well developed on the head and sides of the body. The larvae swam continuously and showed a positive phototaxis and avoidance responses to objects approaching them.

At 6 days the larvae became capable of feeding on small organisms. Frequently, the gut was filled with ingested small organisms. Little yolk mass was left in the abdominal cavity. Commencement of feeding before exhaustion of yolk sac was reported in this species by KASAHARA et al. ${ }^{\text {) }}$

Thereafter, the larvae grew favourably. They attained a total length of about $3.4 \mathrm{~mm}$ at 8 days, $4.0 \mathrm{~mm}$ at 12 days, $5.4 \mathrm{~mm}$ at 20 days and $7.0 \mathrm{~mm}$ at 25 days.

Description of development of gill system At 4 days the gill filaments are becoming recognisable as very small papillae on the gill arches. No blood corpuscles are present at this stage. Red blood cells appear in the afferent branchial artery in the 5-day material but at this stage the secondary lamellae are not formed. The yolk mass is present behind the heart.

Red blood cells appear in the gill filaments of the 6-day material and a little of the yolk mass is still visible within the capsule of the liver. The yolk has completely disappeared at 7 days. Even after 8 days no secondary lamellae have developed on the gill filaments. Their development is clearly recognisable, however, at 12 days and the number of red blood cells in the gill filaments has increased. At the 20-day stage the secondary 
lamellae are clearly formed and have increased in number. Many red blood cells can now be seen in the gill filaments.

It is only in the 25-day material that secondary lamellae are very well developed. Details of the development of different parts of the arterial system have not yet been investigated.

The general appearance of the material under the light microscope indicates that only in material between 8 and 12 days is there some suggestion that the sceondary lamellae of the gill filaments are beginning to play an important part as a gas exchange surface.

Morphometry of gill system The results of the point and intersection counting which was carried out on specimens of the 5,8,12, 20 and 25-day material indicate the increasing volume (points) and surface (intersections) of the gill arches and the gill filament system during development. Absolute values for areas and volumes have not been estimated at present, but analysis of ratios between the different counts indicates the following.

The ratio of intersections with the surface of these structures to points on the arches changes relatively little during development. If anything there is a slight decrease from about 4.0 to 3.0 between 5 and 25 days. By contrast the ratio of intersections with the filament surface to points falling on the filament system changes quite markedly during development. In the earliest stage (5 days) the $I_{f} / P_{f}$ ratio is relatively large but decreases to less than two-thids after 8 days (Fig. 2). This ratio then increases during subsequent stages of development. The change in this particular ratio is indicative of the surface to volume ratio for these structures and a relatively high initial value is to be expected

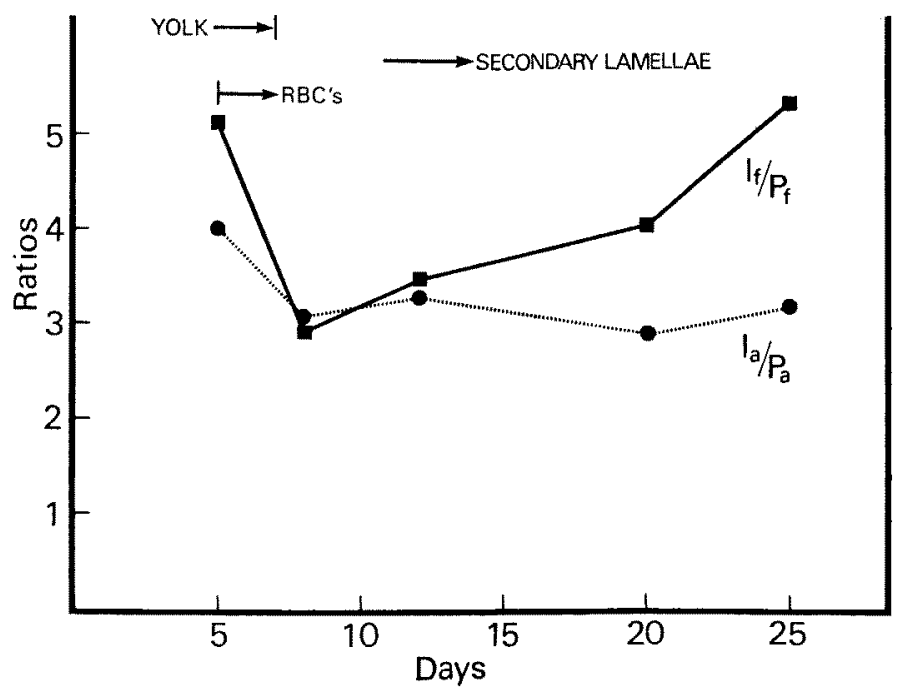

Fig. 2. Plot to show changes in the ratios $I_{a} / P_{a}$ and $I_{f} / P_{f}$ during development of black sea bream. The relative timing of several other events is also indicated. RBC's: Red blood cells in branchial artery. 
because of their small size. With increasing size one would expect the ratio to decrease if growth was isometric. However, during stages later than 8 days the secondary lamellae beg in toappear and produce an increase in surface area. In consequence the $I_{f} / P_{f}$ ratio would be expected to increass as was indeed found using the material available (Fig. 2).

\section{Discussion}

The results of this preliminary study have shown a correlation between stages of gill development recognisable by light microscopy and some simple morphometric measurements. They confirm the theoretical possibility that there would be a stage during the development of the gills at which the surface to volume ratio would become reduced and if this also reflects the situation with respect to the whole body surface, then clearly the fish will experience some restriction in the supply of oxygen at this particular body size. It is said that cutaneous respiration is a significant characteristic in early stages of teleost larvae before the formation of functional gills. Working with yolksac larvae of anchovy, HUNTER $^{8)}$ emphasised that bursts of swimming occurring regularly are related to a respiratory function. The disturbance of stagnant layers would aid gas exchange. The increase in the duration and frequency of swimming associated with food search probably cause a high metabolic rate in larvae. This raises the question of whether cutaneous respiration is sufficient to provide enough oxygen for such active larvae.

It is of interest that at the particular stage ( 8 days) where the surface to volume ratio is least for the gills, experience in fish culture indicates that this is a very sensitive period during development because severe losses are sometimes encountered ${ }^{7}$. It can be concluded therefore that the respiratory problems experienced during the development of black sea bream may be one of the factors governing these losses.

Many studies have been made concerning the factors involved in this critical period (for review see MORRIS ${ }^{9}$ and MAY ${ }^{10}$ ). Most of them have considered changes in the feeding of the larva as a major controlling factor and especially the transfer from endogenous to exogenous sources of food supply. Certainly high mortality at the time of final absorption of yolk has been a common experience in many teleost larvae reared in the laboratory. However, the supply of oxygen must also be of importance for the most efficient utilisation of those metabolites. Some aspects of the respiration of larval fish have been discussed by BLAXTER ${ }^{11)}$ and the change of oxygen uptake with varying activities of larvae has been reviewed for some species.

\section{Acknowledgment}

We thank Dr. M. TANAKA, Seikai Regional Fisheries Research Laboratory, for providing some sections used in this study. 


\section{References}

1) Price, J. W.: Studies State Univ. Ohio, 41, 1-46 (1931).

2) Morgan, M.: J. Morph., 142, 351-363 (1974).

3) De Silva, C.: in "The Early Life History of Fish" (ed. by J. H. S. BLAXTER), Springer-Verlag, Berlin, 1974, pp. 465-485.

4) Hughes, G. M., S. C. Dube, and J. S. DatTa Munshi: J. Zool. Lond., 170, 227-243 (1973).

5) Hughes, G. M., B. R. Singh, R. M. Thakur, and J. S. Datta Munshi: Proc. Ind. Nat. Sci. Acad., 40(B), 379-392 (1974).

6) Hughes, G. M.: Respir. Physiol., 14, 1-25 (1972).

7 Kasahara, S., R. Hirano, and Y. Ohsmma: This Bull., 26, 239-244 (1960).

8) HunTer, J. R.: Fish. Bull. U.S., 70, 821-838 (1972).

9) Morris, R. W.: Bull. Inst. Oceanogr. Monaco, (1082), 1-61 (1956).

10) MAY, R. C.: in "The Early Life History of Fish" (ed. by J. H. S. BlaXTer), Springer-Verlag, Berlin, 1974, pp. 2-19.

11) Blaxter, J. H. S.: in "Fish Physiology" (ed. by W. S. Hoar and D. J. Randall), Vol. 3, Academic Press, New York, 1969, pp. 177-252. 